\title{
Yüksek Serum CA19-9 Seviyeleri ile Seyreden Bir Endometriozis Olgusu
}

\author{
A Case of Endometriosis with High Serum CA19-9 Levels \\ Özlem Nuray Sever', Dilahan Şankır ${ }^{2}$ \\ ${ }^{1}$ Gaziantep Üniversitesi Tip Fakültesi, İç Hastalıkları Ana Bilim, Tibbi Onkoloji Bilim Dalı, Gaziantep \\ ${ }^{2}$ Sanko Üniversitesi Tip Fakültesi, Gaziantep \\ Yazıșma Adresi / Correspondence: \\ Özlem Nuray Sever \\ Gaziantep Üniversitesi Tip Fakültesi, İç Hastalıkları Ana Bilim Dalı, Tıbbi Onkoloji Bilim Dalı, Üniversite Bulvarı 27310 Şehitkamil/Gaziantep \\ T: +903423601200 E-mail: ozlem.sever@hotmail.com
}

Geliş Tarihi / Received : 14.11.2018 Kabul Tarihi / Accepted : 07.02.2019

$\ddot{O} z$

CA19-9 özellikle safra kanalı ve pankreas kanserlerinde yüksek olarak saptanan bir tümör belirtecidir. Bu durumlara ek olarak kolon, mide, over, karaciğer ve özafagus kanserleri gibi diğer malign durumlarda da yüksek seviyelerde saptanır.CA19-9 pankreas kanseri tanısıyla takip edilen hastaların yanıt değerlendirmesinde ve nüksün belirlenmesinde kullanılır. Ayrıca pankreas kanserinin ayırıcı tanısında da yol gösterici olabilir.1-3 CA19-9 seviyesinin yüksek olarak saptanabildiği benign durumlar arasında safra yolu obstrüksiyonu, kolanjit, inflamatuar barsak hastalı̆̆ı, akut veya kronik pankreatit, karaciğer sirozu, kistik fibrozis, tiroid hastalıkları ve periton irritasyonu bulunur.4 Literatürde CA19-9 yüksekliği ile seyreden endometriozis olguları bildirilmiştir, ancak bu olgularda CA19-9 seviyesi ılımlı yüksektir ve CA125 yüksekliği eşlik etmektedir. Bu yazıda yüksek CA19-9 seviyelerinin CA125 seviyeleri ile uyumsuzluk gösterdiği endometriozis tanılı olgumuzu sunmaktayız. ( Sakarya Tip Dergisi 2019, 9(1):180-184)

Anahtar CA 19-9; CA 125; Endometriozis

CA19-9 is a tumor marker that is found to be high in the bile duct and pancreatic cancers. In addition to these conditions, colon, stomach, ovary, liver and other malignant conditions such as esophagus cancers are also detected in high levels. CA19-9 is used in the evaluation of patients followed with diagnosis of pancreatic cancer and determination of recurrence.1-3 It may also be a guide in the differential diagnosis of pancreatic cancer. Benign conditions with high CA19-9 levels may include biliary obstruction, cholangitis, inflammatory bowel disease, acute or chronic pancreatitis, liver cirrhosis, cystic fibrosis, thyroid diseases, and peritoneal irritation. 4 In the literature, endometriosis cases with elevated levels of CA19-9 have been reported, but CA19-9 level is moderately high and CA125 is accompanied by elevation. In this paper, we report a case of endometriosis in which high levels of CA19-9 are incompatible with CA125 levels.In this article, we present our case who was diagnosed with endometriosis with high CA19-9 level. ( Sakarya Med J 2019, 9(1):180-184)

Key words Keywords: CA 19-9; CA 125; Endometriosis 


\section{GİRIŞ}

Karbonhidrat Antijen 19-9 (CA19-9) glikosfingolipid yapida bir antijendir. Başta normal pankreas ve biliyer sistem hücreleri olmak üzere çeşitli dokular tarafından salgılanır. İlk olarak insan kolon kanseri hücre kültüründe monoklonal antikor yöntemiyle tanımlanmıştır. Daha sonraları CA19-9 düzeylerinin pankreas, kolon, over, akciğer ve karaciğer malignitelerinin yanı sıra siroz, hepatit, kolesistit gibi hepatobiliyer sistemin benign hastalıklarında, renal yetmezlik, plevral efüzyon, pnömoni ve milier tüberküloz gibi benign durumlarda da yükselebileceği gösterilmiştir. Nüfusun \%5'inde vücudun CA19-9 üretmediği bilinmektedir. Sağlıklı bireylerde de yüksek seviyeler görülebilmektedir. ${ }^{5} \mathrm{Bu}$ tümör belirtecinin pankreas kanseri için "cutoff ” değeri $37 \mathrm{U} / \mathrm{mL}$ olarak alındığında duyarlılı̆̆ $\% 80$, özgüllüğü \%90 ve biliyer sistem kanserleri için duyarlıllğ 1 \%60-70 olarak bildirilmiştir. Üst sınır $\bigotimes 1000 \mathrm{U} / \mathrm{mL}$ olarak alındığında ise pankreas kanseri için özgüllüğünün $\% 100$ 'lere yaklaştı̆̆ı görülmüştür. ${ }^{6}$

\section{OLGU SUNUMU}

23 yaşında kadın hasta; Nisan 2018'de alt batında başlayıp suprapubik bölgeye yayılan, ani ve şiddetli ağrı şikâyetiyle acil servise başvurdu. Anamnezinde bulantı, kusma, ishal yoktu; menstrüasyon kanaması 3 gün sonra idi. Yapılan fizik muayenesinde genel durumu iyi, vital bulguları normal sınırlarda, hepatosplenomegali yok, batında asit yok, bilateral kostovertebral açı hassasiyeti yok, batın alt kadranlarda palpasyonla hassasiyet mevcuttu, defans ve rebound yoktu. Çekilen ayakta direkt batın grafisinde yaygın gaz saptandı. Ancak şiddetli ağrıya sebep olmayacağı düşünülerek alt batın bilgisayarlı tomografisi çekildi. BT'de sol overde 4-5 cm çapinda over kisti saptandi. Uygulanan analjezik tedavi ile ağrısı azalan hasta jinekoloji kontrolü önerisiyle acil servisten taburcu edildi.

Ağrısı devam eden hasta bir gün sonra jinekoloji kontrolüne geldi. Yapılan fizik muayenesinde sol alt kadranda defans ve rebound tespit edildi. Transvaginal ultrasonografide uterus doğal, sağ over doğal, sol overde $5,3^{\star} 3,5 \mathrm{~cm}$ hemorajik kist ve douglasta minimal sıvı saptandı. Yatışı yapılan hastanın oral alımı kesilerek takibe alındı. Ertesi gün yapılan fizik muayenede akut ağrının kaybolduğu görülen hastada rüptür olmadığ düşünüldü ve tümör belirteçleri istendi. CA19-9 düzeyi 1237,5 ng/ml olarak saptand1, yapılan fizik muayenesi normal sinırlarda olan, vital bulguları stabil olan ve ağrısı olmayan hasta 1 hafta sonra poliklinik kontrolüne gelmek üzere taburcu edildi.

1 hafta sonra kadın hastalıkları polikliniğine başvuran hastadan tekrar tümör belirteçleri istendi. Yapılan fizik muayene ve ultrasonografi sonucu sol overde daha önce saptanan kistin endometrioma olduğu saptandı (Resim 1). Bu dönemde bakılan CA19-9 düzeyi 1429 ng/ml saptanan hastaya ileri tetkik yaptırmak üzere Gastroenteroloji ve Tibbi Onkoloji poliklinik kontrolü önerildi.

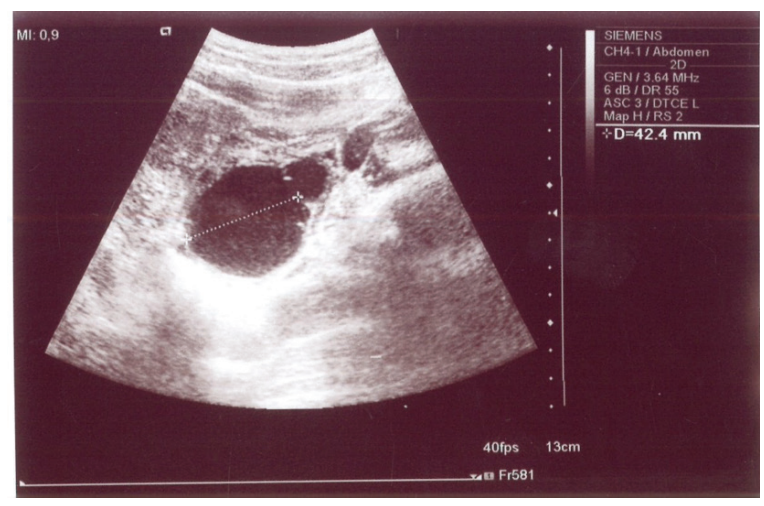

Resim 1: Trans vaginal ultrasonografi (TVUSG): Sol Overde 5,3*3,5 $\mathrm{cm}$ boyutunda endometrioma

Gastroenteroloji konsültasyonu sonucu hastaya devam eden CA19-9 yüksekliği nedeniyle pankreas, safra yolları ve kolonu daha iyi değerlendirmek amacıyla Trifazik Bilgisayarlı Batın Tomografisi ve endoskopik inceleme önerildi. Çekilen Trifazik batın BT'de ve yapılan alt ve üst gastrointestinal sistem endoskopilerinde endometrioma ve myoma uteri dışında patoloji saptanmadı (Resim 2).

Tibbi onkoloji konsültasyonu sonucu CEA, CA125 ve CA19-9 seviyelerinin birbiriyle uyumsuz olduğu ifade edildi. Şikâyeti olmayan hastanın 1 ay sonra tümör belir- 
teçlerini tekrarlaması istendi. CA19-9 yüksekliği devam ettiği taktirde pozitron emisyon tomografisi ve likit biyopsi seçeneklerinin değerlendirilebileceği belirtildi.

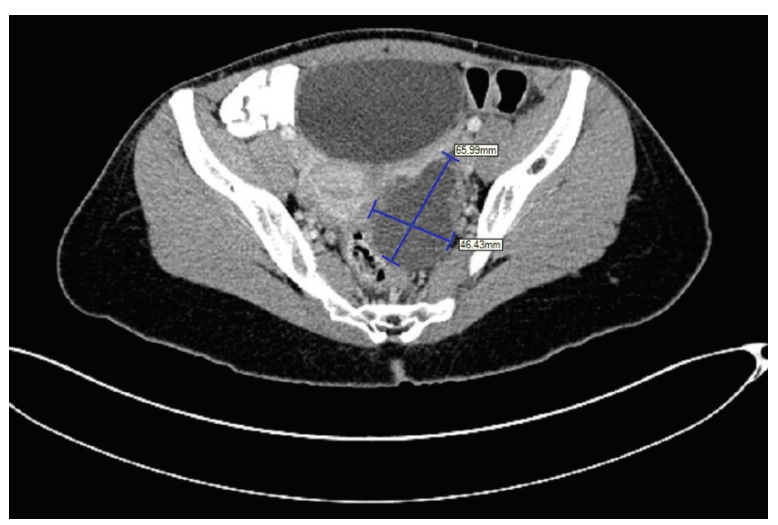

Resim 2: Alt Abdomen Trifazik Bilgisayarlı Tomografi: Sol Overde $65,9 \star 46,4 \mathrm{~cm}$ boyutunda endometrioma

24/04/2018 ve 25/05/2018 tarihlerinde tekrarlanan CA199 seviyelerinin giderek düştüğü saptanan hastaya onkolojik açıdan ileri tetkik önerilmedi, ancak jinekoloji kontrolü önerildi. Aşağıdaki tabloda hastanın tümör belirteçleri özetlenmiştir (Tablo 1). Yapılan TVUSG ve muayene sonrasi sol overde 5,6*3,8 $\mathrm{mm}$ endometrioma, rekto-vaginal derin endometriozis ve uterusta iki adet milimetrik intramural myom tespit edildi. Hastanın CA19-9 yüksekliğinin endometriozise bağlı olduğu düşünüldü. Oral kontraseptif tedavi başlanan hastaya düzenli karaciğer fonksiyon testleri yaptırması ve jinekoloji takibi önerildi.

\section{TARTIŞMA}

CA19-9 başta tükrük bezleri, biliyer epitel, pankreatik duktal epitel ve metaplastik mezotelyal epitel gibi glandü- ler epitel hücrelerinde bulunan bir glikoproteindir. Pankreas adenokarsinomu için önemli bir gösterge olan CA199, pankreasın hem normal hem de tümör içeren epitel hücrelerinden kaynaklanabilir. Pankreas kanseri ile karışacak hastalıkların ayırıcı tanısı ve yine pankreas kanserinde tedaviye cevap ve nüksün değerlendirilmesinde kullanılır. Pankreas kanserleri dışında, safra kanalı, kolon, mide, over, hepatosellüler ve özafagus kanserleri gibi malign durumlarda da yüksek seviyelerde görülebilen bir tümör belirtecidir.

Çok yüksek CA19-9 ( $\ 1.000 \mathrm{U} / \mathrm{ml})$ seviyeleri pankreas kanseri olgularında çoğu zaman rezeksiyon şansı olmayan ileri tümörü işaret eder. Postoperatif CA19-9 seviyesinde düşüş olması ise iyi sağ kalım ile koreledir.

Literatürde CA19-9 yüksekliği ile seyreden pankreas kanseri dışında çeşitli olgu sunumları bulunmaktadır. Hüseyin Demirsoy ve arkadaşları CA19-9 yüksekliğine sebep olan dalak kisti olgusu sunmuştur. Bu olguda sağ hipokondriumda ağrı nedeniyle tetkik edilen hastanın yüksek CA19-9 seviyesi ile birlikte çekilen Manyetik Rezonans batın görüntülemesinde dalak kisti saptamışlardır. Hastanın CA19-9 yüksekliğinin daha önceden bilinen dalak kistinin büyümesine bağlı olduğunu bildirmişlerdir. ${ }^{2}$

M. Sait Dağ ve arkadaşları karın ağrısı, ateş ve sarılık şikayetleri ile başvuran hastanın fizik muayenesinde epigastrik ve sağ hipokondriak bölgede ağrı ve hassasiyet saptamışlardır. Bu hastada lökositoz, kolestaz enzimlerinde yükseklik ile beraber CA19-9 yüksekliği saptamışlardır. Hastaya yapılan hepatobiliyer ultrasonografi sonucu safra kesesi ve

\begin{tabular}{|l|c|c|c|c|c|}
\hline \multicolumn{6}{|c|}{ Tablo 1: Gastrointestinal patolojisi olmayan endometriozis tanılı hastanın takiplerdeki tümör belirteçleri } \\
\hline TÜMÖR BELİRTECİ & 02.04 .2018 & 09.04 .2018 & 24.04 .2018 & 25.05 .2018 & REFERANS ARALIĞI \\
\hline CEA $\quad(\mathrm{ng} / \mathrm{mL})$ & 0,53 & 0,80 & - & 0,54 & $\begin{array}{c}\text { Sigara içmeyen }<2,5 \\
\text { Sigara içen }<5,0\end{array}$ \\
\hline CA $19.9(\mathrm{ng} / \mathrm{mL})$ & 1237,5 & 1429,26 & 357,18 & 264,03 & $--<37$ \\
\hline CA-125 $(\mathrm{ng} / \mathrm{mL})$ & 89,7 & 34,2 & 14,9 & 15,1 & $--<30,2$ \\
\hline CA $15.3(\mathrm{ng} / \mathrm{mL})$ & 19,9 & - & 27,2 & - & $--<32,4$ \\
\hline
\end{tabular}


koledokta taşlar, koledok ve intrahepatik safra yollarında dilatasyon izlemişler. ERCP uyguladıkları hastada CA19-9 seviyelerinin 10 gün içerisinde normal seviyelere düştüğünü bildirmişler. ${ }^{7}$

Literatürde CA19-9 ve CA 125 yüksekliği ile seyreden endometrioma olguları ile ilgili yayınlar mevcuttur. Bu yayınlarda CA19-9 yüksekliği ile endometriozisin tanısında faydalı bir belirteç olduğu ve endometriozisin ciddiyeti ile CA19-9 düzeylerinin korele seyrettiği bildirilmiştir. Ancak bu yayınlara bakıldığında CA19-9 ve CA125 yüksekliğinin benzer düzeylerde olduğu görülmektedir. ${ }^{1,8-10}$ Kurdoğlu ve ark. yaptıkları retrospektif çalışmada endometriozisli olgularda tüm evrelerde CA19-9 seviyelerinin yüksek olduğunu saptamışlardır. Ancak araştırmacılar CA125 seviyelerinin Evre IV endometrioziste yüksek olmasına rağmen Evre I endometrioziste normal saptadıklarını bildirmişlerdir. Çalışmanın sonunda her iki tümör belirtecinin de sadece ciddi hastalıkta (Evre III ve IV) prediktif değeri olduğunu savunmuşlardır. ${ }^{10}$ Bizim olgumuzda ise CA 125 değerindeki hafif-1lımlı yüksekliğe rağmen CA19-9 değerinde belirgin yükseklik söz konusu idi. Ayrıca bu çalışmalarda bildirilen CA19-9 seviyeleri normal değerden yüksek olmasına rağmen bizim hastamızdaki gibi aşırı yüksek seviyelerde değildi.

Hastamızın takiplerinde endometriozis tedavisi amaçlı Dienogest $2 \mathrm{mg} /$ gün tedavisi başlanması ile birlikte CA199 ve CA125 düzeyleri normal sınırlara düştü. Literatürde Danazol ve LHRH agonistleri ile tedaviden sonra CA125 düzeylerinin düştüğü ve rekürrens durumunda tekrar yükseldiği ile ilgili yayınlar ${ }^{11}$ bulunmasına rağmen tedavi ve CA19-9 düzeyleri arasındaki ilişki ile ilgili yayın bulunmamaktadır. Bizim olgumuzda da tedavi ile endometriotrik depozitlerin inaktive olduğu ve buna bağlı olarak CA19-9 düzeylerinin azaldığı düşünülmüştür.

Bizim olgumuzda batın ultrasonografisi ve bilgisayarlı tomografi görüntülemeleri sonucu gastrointestinal sistem organlarında patoloji olmadığı görüldü. Hastanın yapılan jinekolojik muayene ve incelemeleri sonucu endometrioma ve endometriozis tespit edildi. Mevcut CA19-9 yüksekliği bu sebebe bağlı olduğu düşünüldü. Ayrıca hastanın diğer tümör belirteçleri ile birlikte değerlendirildiğinde uyumsuz CA19-9 yüksekliği mevcuttu.

Tümör belirteçlerinin sadece malign hastalıklarda yükselmeyebileceği, bir çok benign durumda da yükselebileceği akılda tutulmalıdır. Malignite tanısı olan hastalarda tedavi yanıtının ve nükslerin değerlendirilmesinde fayda olmakla birlikte tanı konmamış hastalarda tanısal rolünün olabileceği akılda tutulmalıdır. 
Sakarya Tip Dergisi 2019;9(1):180-184

SEVER ve Ark. Yüksek Serum CA19-9 Seviyeleri ile Seyreden Bir Endometriozis Olgusu

\section{Kaynaklar}

1. Dağ MS, Öztürk ZA, Çam H, Koruk İ, Kepekçi Y, Kadayıf̧̧ı A. Are Very High Levels of CA 19-9 Always Indicators for Malignancy?: Akademik Geraitri Dergisi 2012; 4(3): 158-161.

2. Demirsoy H, Eminler AT, Ercan M, Uslan Mİ, Köksal AȘ, Parlak E. Splenic cyst causing high levels of pathognomonic CA 19-9: Akademik Gastroenteroloji Dergisi 2017; 16(3): 118-120.

3. Cwik G, Wallner G, Skoczylas T, Krzyzanowski M, Ciechainski A, Madro P. Elevated tumor marker CA 19-9 in the differential diagnosis of pancreatic mass lesions: Ann Univ Mariae Curie Sklodowska Med. 2004;59(2):213-218.

4. Endometriosis. Mayo Clinic. https://www.mayoclinic.org/diseases-conditions/endometriosis/symptoms-causes/syc-20354656 Erişim Tarihi: 24/06/2018

5. Dai X, Jin C, Hu Y, Zhang Q, Yan X, Zhu F, Lin F. High CA-125 and CA19-9 levels in spontaneous ruptured ovarian endometriomas: Clin Chim Acta. 2015 Oct 23;450:362-365.

6. Steinberg W. The clinical utility of the the CA 19-9 tumor-associated antigen. Am J Gastroenterol 1990; 85: 350-355.
7. Harada T, Kubota T, Aso T. Usefulness of CA19-9 versus CA125 for the diagnosis of endometriosis. Fertility and Sterility 2002 Oct;78(4):733-739.

8. Duran M, Kosus A, Kosus N, Duvan C, Kafali H, Yllmaz Ș. Treatment of Ruptured Ovarian Endometrioma with Extremely High CA 125, Moderately High CA 19-9 and CA 15-3 Level: J Clin Anal Med 2013:4(supple 3): 299-301.

9. Bayramov V, Şükür YE, Pabucçu E, Atabekoğlu CS. Extremely Elevated CA-125 and CA 19-9 in Endometrioma: A Case Series. J Turk Soc Obstet Gynecol 2010 7;1:45-48

10. Kurdoglu Z, Gürsoy R, Kurdoglu M, Erdem M, Erdem Ö, Erdem A. Comparison of the clinical value of CA 19-9 versus CA 125 for the diagnosis of endometriosis. Fertility and Sterility 2009-11-01;92:5:1761-1763.

11. Acien P, Shaw RW, Irvine L, Burford G, Gardner R. CA125 levels in endometriosis patients before, during and after treatment with Danazol or LHRH agonists. European Journal of Obstetrics and Gynecology and Reproductive Biology 1989:32; 241-246 